\title{
Molecular Design Realizing Very Fast Reverse Intersystem Crossing in Purely Organic Emitter
}

\author{
Yoshimasa Wada, Hiromichi Nakagawa, Soma Matsumoto, Yasuaki Wakisaka and Hironori Kaji* \\ Institute for Chemical Research, Kyoto University, Uji, Kyoto 611-0011, Japan
}

\begin{abstract}
Reverse intersystem crossing (RISC), originally considered forbidden in purely organic materials, has been recently enabled by minimizing the energy gap between the lowest singlet excited state $\left(\mathrm{S}_{1}\right)$ and lowest triplet state $\left(\mathrm{T}_{1}\right)$ in thermally activated delayed fluorescence (TADF) systems. However, direct spin-inversion between $S_{1}$ and $T_{1}$ is still inefficient when both states are of the same charge transfer (CT) nature (i.e. ${ }^{1} \mathrm{CT}$ and ${ }^{3} \mathrm{CT}$, respectively). Intervention of locally excited triplet states $\left({ }^{3} \mathrm{LE}\right)$ between ${ }^{1} \mathrm{CT}$ and ${ }^{3} \mathrm{CT}$ is expected to trigger fast spin-flip. Here, we report on the systematic-design of the ideal TADF molecules with near-degenerate ${ }^{1} \mathrm{CT},{ }^{3} \mathrm{CT}$ and ${ }^{3} \mathrm{LE}$ states by controlling the through-space distance between the donor and acceptor segments in a molecule with tilted intersegment angles. The new system realizes very fast RISC with a rate constant $\left(k_{\mathrm{RISC}}\right)$ of $1.2 \times 10^{7} \mathrm{~s}^{-1}$. The large $k_{\mathrm{RISC}}$ of the emitter resulted in great device performance in the applications to blue TADF assisted fluorescence organic light-emitting diodes (OLEDs) as well as TADF-emitter OLEDs.
\end{abstract}



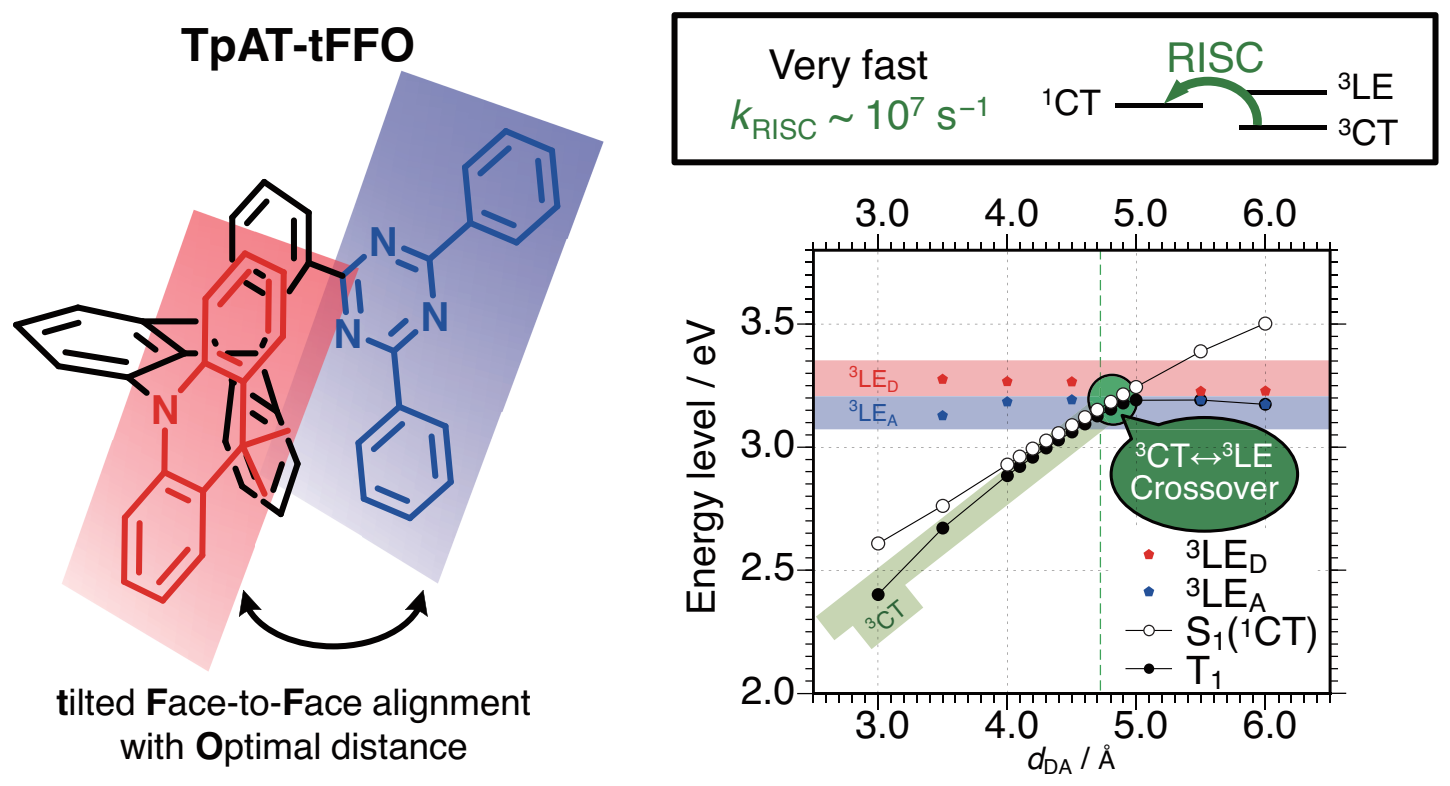


\section{INTRODUCTION}

Highly efficient emission in organic light emitting diodes (OLEDs) requires conversion of triplet excitons into light because triplet excitons account for $75 \%$ of all excitons generated by charge recombination of holes and electrons in OLEDs. One strategy for making use of triplets is to use transition-metal-based phosphorescent materials, mediated by the heavy atom effect, ${ }^{1}$ and this strategy has realized high performance OLEDs. ${ }^{2}$ Recently, an alternative approach was demonstrated whereby emitters fluoresce from triplet states via thermal up-conversion to the singlet state. ${ }^{3}$ The system, named thermally activated delayed fluorescence (TADF), ${ }^{4}$ has since been vigorously investigated. ${ }^{5}$ Although TADF materials containing heavy-metals (e.g. $\mathrm{Cu}, \mathrm{Pd}, \mathrm{Ag}, \mathrm{Sn}$ and $\mathrm{Au}$ ) have been shown excellent performances, ${ }^{6}$ even non-metal TADF systems have achieved internal quantum efficiencies of $100 \%$ in experimental OLEDs. ${ }^{3,7}$ In both metal-containing and non-metal cases, the energy gap between the lowest excited singlet $\left(\mathrm{S}_{1}\right)$ and the lowest triplet $\left(\mathrm{T}_{1}\right)$ states, termed $\Delta E_{\mathrm{ST}}$, should be small, typically $<$ $0.1 \mathrm{eV}$, to accomplish spin up-conversion from $\mathrm{T}_{1}$ to $\mathrm{S}_{1}$ by reverse intersystem crossing (RISC). A small $\Delta E_{\mathrm{ST}}$ can be achieved simply by separating the highest occupied molecular orbital (HOMO) and lowest unoccupied molecular orbital (LUMO) of the emitter molecule or those of different donor and acceptor molecules. At the initial stage of TADF research, and even now, HOMO-LUMO separation has been typically realized by covalently-bonding electron donor and acceptor units.

However, in terms of conservation of angular momentum, intersystem crossing (ISC) and RISC between $S_{1}$ and $T_{1}$ states having the same configuration character are theoretically spin-forbidden, known as El-Sayed rule. ${ }^{8}$ Therefore, the rate constants of RISC $\left(k_{\text {RISC }}\right)$ cannot be great in TADF systems having similar CT-type $\mathrm{S}_{1}$ and $\mathrm{T}_{1}$ states $\left({ }^{1} \mathrm{CT}\right.$ and ${ }^{3} \mathrm{CT}$, respectively). Recently, inclusion of locally excited triplet $\left({ }^{3} \mathrm{LE}\right)$ states has been reported to accelerates RISC $;{ }^{9}$ the inherently forbidden ${ }^{3} \mathrm{CT}$ to ${ }^{1} \mathrm{CT}$ transition $\left({ }^{3} \mathrm{CT} \nrightarrow{ }^{1} \mathrm{CT}\right)$ becomes effective by intervening ${ }^{3} \mathrm{LE}\left({ }^{3} \mathrm{CT} \rightarrow{ }^{3} \mathrm{LE} \rightarrow{ }^{1} \mathrm{CT}\right)$. Hence, the best 
performance can be expected when we realize energy level matching of these three states, i.e., $E\left({ }^{1} \mathrm{CT}\right) \approx$ $E\left({ }^{3} \mathrm{CT}\right) \approx E\left({ }^{3} \mathrm{LE}\right)$, where $E(\mathrm{X})$ means the energy level of $\mathrm{X}$ state. Here, we propose a systematic design principle to realize the ideal TADF system.

In designing ideal TADF molecules, we conceptually consider "tilted" face-to-face (tFF) alignment of donor and acceptor segments. Figure 1a shows an example, composed of 9,9-dimethyl-9,10dihydroAcridine (abbreviated as $\mathbf{A}$ and colored red) and 2,4-diphenyl-1,3,5-Triazine (abbreviated as $\mathbf{T}$ and colored blue) as donor and acceptor components, respectively. The HOMO on the A segment and the LUMO on the $\mathbf{T}$ segment spatially overlap when they are in close proximity, resulting in both $\mathrm{S}_{1}$ and $\mathrm{T}_{1}$ being through-space $\mathrm{CT}$ states ${ }^{10}\left({ }^{1} \mathrm{CT}\right.$ and ${ }^{3} \mathrm{CT}$, respectively). As calculated by density functional theory (DFT) and time dependent DFT (TD-DFT) with Gaussian16 (LC- $\omega$ PBE/6-31+G(d) level of theory), both energy levels, $E\left({ }^{1} \mathrm{CT}\right)$ and $E\left({ }^{3} \mathrm{CT}\right)$, increased as the distance between the donor and acceptor $\left(d_{\mathrm{DA}}\right)$ increased, as shown at the top of Figure 1b. Here, $d_{\mathrm{DA}}$ is defined as the distance between the nitrogen in $\mathbf{A}$ and the carbon in $\mathbf{T}$, emphasized by black boldface at the top of Figure 1a. The energy difference between ${ }^{3} \mathrm{CT}$ and ${ }^{1} \mathrm{CT}, \Delta E\left({ }^{3} \mathrm{CT} \rightarrow{ }^{1} \mathrm{CT}\right.$ ), decreases with increasing $d_{\mathrm{DA}}$ (Figure $1 \mathrm{~b}$ top and middle). 
(a)

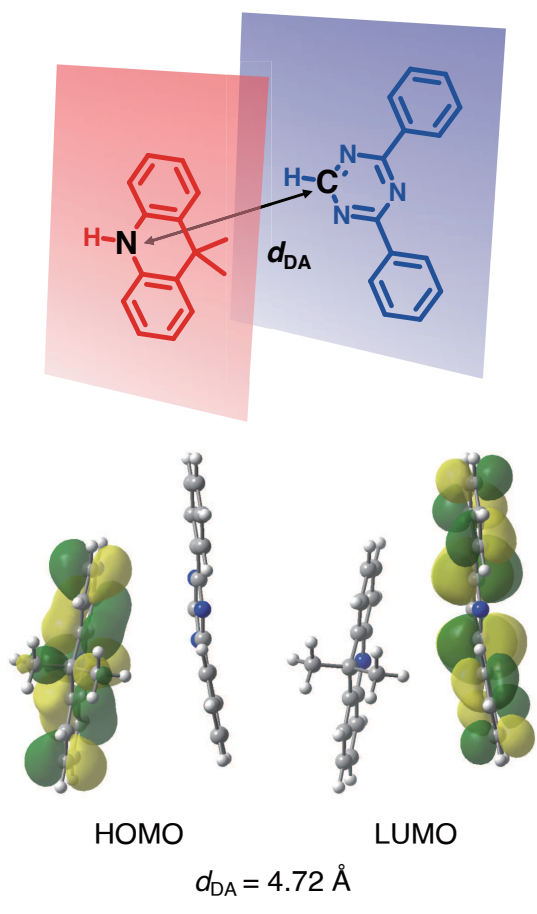

(b)

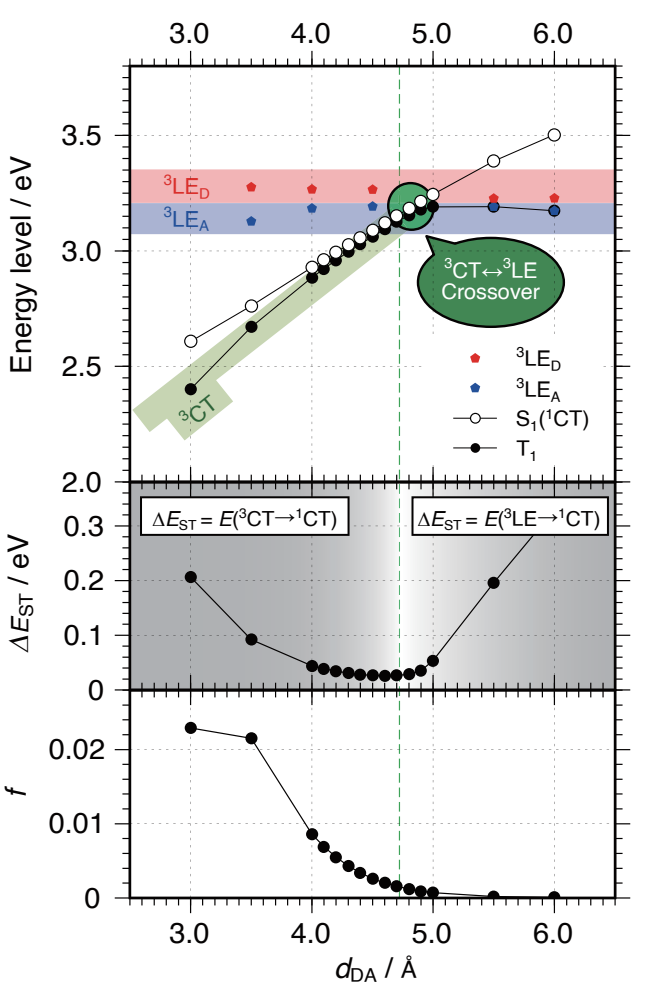

Figure 1. Conceptual molecular design. (a) Fragment structures of donor (red) and acceptor (blue) are shown. Donor and acceptor pair is tilted $\left(\sim 10^{\circ}\right)$ face-to-face alignment spatially separated with certain distance $\left(d_{\mathrm{DA}}\right)$. HOMO and LUMO with $d_{\mathrm{DA}}$ of $4.72 \AA$ are also shown. (b) DFT-calculated energy levels of $\mathrm{S}_{1}, \mathrm{~T}_{1},{ }^{3} \mathrm{LE}_{\mathrm{D}},{ }^{3} \mathrm{LE}_{\mathrm{A}}$ (top), $\Delta E_{\mathrm{ST}}$ (middle) and $f$ (bottom) as a function of $d_{\mathrm{DA}}$, where ${ }^{3} \mathrm{LE}_{\mathrm{D}}$ and ${ }^{3} \mathrm{LE}_{\mathrm{A}}$ denote the ${ }^{3}$ LE states on donor and acceptor fragments, respectively. Green dashed line indicates $d_{\mathrm{DA}}=$ $4.72 \AA$, which corresponds to the $d_{\mathrm{DA}}$ of DFT optimized structure for TpAT-tFFO at the ground state.

Here, $\Delta E(\mathrm{X} \rightarrow \mathrm{Y})$ indicates the energy change from the $\mathrm{X}$ to $\mathrm{Y}$ states. This value is defined as positive for an uphill transition and negative for a downhill transition. When $d_{\mathrm{DA}}$ is greater than $3.5 \AA$, a value of $\Delta E\left({ }^{3} \mathrm{CT} \rightarrow{ }^{1} \mathrm{CT}\right)$ less than $0.1 \mathrm{eV}$ is realized and a sufficiently small $\Delta E\left({ }^{3} \mathrm{CT} \rightarrow{ }^{1} \mathrm{CT}\right)$ is obtained at $d_{\mathrm{DA}}>$ 4.0 A. Unlike the $d_{\mathrm{DA}}$ dependence of $E\left({ }^{1} \mathrm{CT}\right)$ and $E\left({ }^{3} \mathrm{CT}\right), E\left({ }^{3} \mathrm{LE}\right)$ only weakly depends on $d_{\mathrm{DA}}$ (at the top 
of Figure $1 \mathrm{~b})$. Therefore, both $E\left({ }^{1} \mathrm{CT}\right)$ and $E\left({ }^{3} \mathrm{CT}\right)$ approach the originally higher lying $E\left({ }^{3} \mathrm{LE}\right)$ as $d_{\mathrm{DA}}$ increases. Finally, the energy level matching of the three states occurs at approximately $d_{\mathrm{DA}} \approx 4.7 \AA$.

This example demonstrates that the above-mentioned ideal situation, $E\left({ }^{1} \mathrm{CT}\right) \approx E\left({ }^{3} \mathrm{CT}\right) \approx E\left({ }^{3} \mathrm{LE}\right)$, can be intentionally realized by optimizing the $d_{\mathrm{DA}}$. However, an additional requirement should be satisfied to realize very fast RISC. As shown later, spin-orbit coupling matrix element values (SOCMEVs) are negligibly small, not only between ${ }^{1} \mathrm{CT}$ and ${ }^{3} \mathrm{CT}$ but also between ${ }^{1} \mathrm{CT}$ and ${ }^{3} \mathrm{LE}$, when $\mathrm{A}$ and $\mathbf{T}$ segments are in a completely parallel Face-to-Face (cFF) alignment with each other. Thus, the transition is still spin-forbidden even between ${ }^{1} \mathrm{CT}$ and ${ }^{3} \mathrm{LE}$ for the cFF alignment. This problem can be solved by simply "tilting" the face-to-face alignment. Although the SOCMEV remains negligible between ${ }^{1} \mathrm{CT}$ and ${ }^{3} \mathrm{CT}$ irrespective of the alignment, the SOCMEV between ${ }^{1} \mathrm{CT}$ and ${ }^{3} \mathrm{LE}$ becomes notable for the "tilted Faceto-Face" (tFF) alignment.

Here, we selected triptycene (Tp) as the scaffold for realizing tFF donor-acceptor alignment with an "Optimized" distance (tFFO). The new molecule, composed of Tp, A and T segments with tFFO structure, is named "TpAT-tFFO". The A and T segments are introduced at the 1st and 8th positions of Tp (Figure. 2a). The $d_{\mathrm{DA}}$ of $4.72 \AA$ and tilted face-to-face donor-acceptor alignment are expected from the DFT optimized structure (Figure. 2b). The calculated $\Delta E_{\mathrm{ST}}=\Delta E\left({ }^{3} \mathrm{CT} \rightarrow{ }^{1} \mathrm{CT}\right)$ of $0.019 \mathrm{eV}($ Table S1) is satisfactory small, and $\Delta E\left({ }^{3} \mathrm{CT} \rightarrow{ }^{3} \mathrm{LE}\right)$ and $\Delta E\left({ }^{3} \mathrm{LE} \rightarrow{ }^{1} \mathrm{CT}\right)$ were also small. The tilted face-to-face donor-acceptor alignment provides a much greater SOCMEV than that of the case of completely parallel face-to-face alignment. The oscillator strength, $f$, decreases with increasing $d_{\mathrm{DA}}$ (Figure. 1b, at the bottom), but the experimentally-obtained photoluminescence (PL) quantum yields (PLQY) of TpATtFFO were satisfactory at $84 \%$ and $76 \%$ in toluene solution and a doped film, respectively. The PLQY was as high as $71 \%$ even for a neat film. A $k_{\text {RISC }}$ exceeding $10^{7} \mathrm{~s}^{-1}$ was realized from our newly designed molecule, TpAT-tFFO. 


\section{RESULTS AND DISCUSSION}

Molecular design and Calculations. Figure 2a shows the molecular structure of TpAT-tFFO, where A (red) and $\mathbf{T}$ (blue) are intended to serve as donor and acceptor fragments, respectively. The DFToptimized structure in Figure 2b was obtained at the B3LYP/6-31G(d) level of theory with a polarizable continuum model (PCM) in toluene implemented in Gaussian 16 program package. ${ }^{11}$ By introducing A and $\mathbf{T}$ at the 1st and 8th positions of $\mathbf{T p}$, a tilted face-to-face donor-acceptor alignment with mostly optimized $d_{\mathrm{DA}}$ was realized, as we had designed for. For the TD-DFT calculations, Brédas and coworkers have previously reported that a long-range corrected density functional, LC- $\omega$ PBE with the optimized range-separation parameter $\omega$ for the target molecules, accurately describes the excited state energy of TADF system. ${ }^{9 g, 12}$ Therefore, for the excited state calculation, we used a combination of the LC- $\omega$ PBE functional and $6-31+\mathrm{G}(\mathrm{d})$ basis set, the same combination with Brédas' calculations. The results of the TD-DFT calculations are summarized in Table S1. The optimized value of $\omega$ for TpATtFFO was $0.1664 \mathrm{Bohr}^{-1}$ (Figure S1a). A small value of $\Delta E\left({ }^{3} \mathrm{CT} \rightarrow{ }^{1} \mathrm{CT}\right.$ ) of $0.019 \mathrm{eV}$ was achieved owing to the spatially separated HOMO and LUMO (Figure 2b). Moreover, the ${ }^{3}$ LE state is also closelying as we designed; $\Delta E\left({ }^{3} \mathrm{CT} \rightarrow{ }^{3} \mathrm{LE}\right)$ and $\Delta E\left({ }^{3} \mathrm{LE} \rightarrow{ }^{1} \mathrm{CT}\right)$ were 0.075 and $-0.057 \mathrm{eV}$, respectively. 
(a)

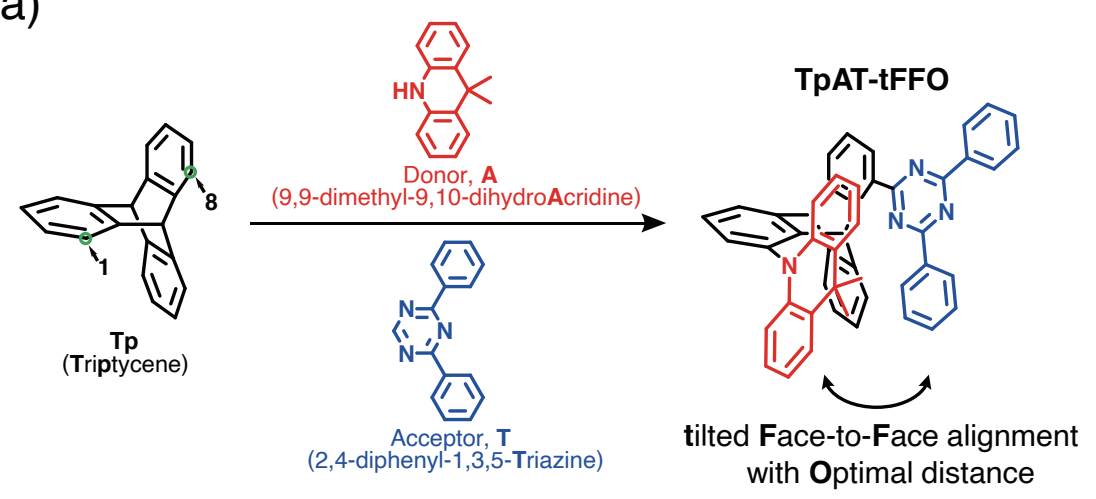

(b)

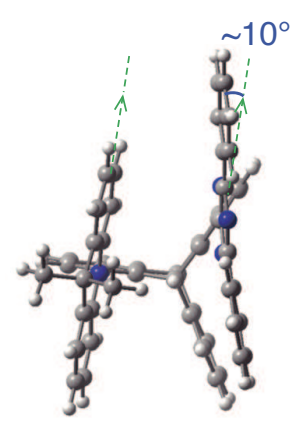

Side view

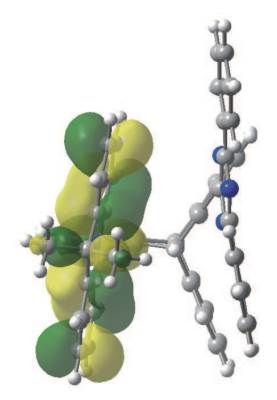

HOMO

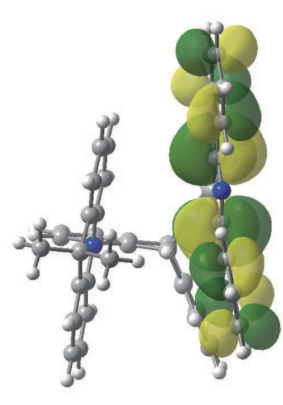

LUMO

Figure 2. Molecular structure and its frontier molecular orbitals. (a) Schematic molecular structure of TpAT-tFFO. (b) DFT-optimized structure of TpAT-tFFO (side view, HOMO, and LUMO).

The Tp scaffold created a tilted donor-acceptor alignment as described above. The tilt angle (i.e. the angle between the normal vectors of $\mathbf{A}$ and $\mathbf{T}$ segments) of TpAT-tFFO was $\sim 10^{\circ}$ (Figure $2 b$, shown as the angle between the intersegment planes in the figure for clarity). We calculated the SOCMEV for TpAT-tFFO. We also calculated it for the donor-acceptor (A-T) pair without $\mathbf{T p}$ in the cFF alignment with $d_{\mathrm{DA}}$ of $4.72 \AA$ (AT-cFFO), where the $\pi$-planes of the $\mathbf{A}$ and $\mathbf{T}$ segments were in a completely parallel alignment, as shown in Figure S2b. Similar to Brédas' calculations, ${ }^{9 \mathrm{~g}}$ we calculated SOCMEV with the ADF2018 package. The LCY- $\omega$ PBE functional and Slater-type all-electron TZP were used for the calculation, where the range parameter, $\gamma,{ }^{13}$ was optimized to be 0.213 (details of the optimization are provided in the Supporting Information). When the $\mathbf{A}$ and $\mathbf{T}$ segments were in the completely 
parallel alignment, an SOCMEV of $0.00 \mathrm{~cm}^{-1}$ was obtained between ${ }^{1} \mathrm{CT}$ and ${ }^{3} \mathrm{CT}$. Furthermore, the SOCMEV was small, $0.05 \mathrm{~cm}^{-1}$, even between ${ }^{1} \mathrm{CT}$ and ${ }^{3} \mathrm{LE}$. This result provides crucial insight that transitions between ${ }^{1} \mathrm{CT}$ and ${ }^{3} \mathrm{LE}$ are not always allowed. On the contrary, TpAT-tFFO exhibited a markedly enhanced SOCMEV of $0.61 \mathrm{~cm}^{-1}$ between ${ }^{1} \mathrm{CT}$ and ${ }^{3} \mathrm{LE}$ owing to the tilting of the donoracceptor alignment. The SOCMEV was still zero between ${ }^{1} \mathrm{CT}$ and ${ }^{3} \mathrm{CT}$ even for the tilted alignment.

These calculations demonstrate that effective RISC is expected for our tFFO molecular design strategy, which simultaneously achieves a very close energy level alignment, i.e. $E\left({ }^{1} \mathrm{CT}\right) \approx E\left({ }^{3} \mathrm{CT}\right) \approx$ $E\left({ }^{3} \mathrm{LE}\right)$, and significant SOCMEV between ${ }^{1} \mathrm{CT}$ and ${ }^{3} \mathrm{LE}$. We successfully synthesized TpAT-tFFO and performed photophysical measurements after train sublimation. Details of the synthesis and characterization of TpAT-tFFO are provided in the Supporting Information.

Photophysical properties. One interesting feature of TpAT-tFFO is a weak CT absorption observed in the visible wavelength region, despite the very efficient emission. Figure 3a shows UV-vis absorption and emission spectra of TpAT-tFFO in toluene solution at a concentration of $10^{-4} \mathrm{M}$. We used a concentration an order of magnitude larger than our standard to detect the weak CT absorption clearly. Intense $\pi \pi^{*}$-type absorption ${ }^{14}$ was observed in the ultraviolet region around $\sim 300 \mathrm{~nm}$ with a molar absorption coefficient $\varepsilon$ around $2 \times 10^{4} \mathrm{~cm}^{-1} \mathrm{M}^{-1}$, whereas absorption from 350 to $450 \mathrm{~nm}$ was two orders of magnitude smaller $\left(\varepsilon \sim 2 \times 10^{2} \mathrm{~cm}^{-1} \mathrm{M}^{-1}\right)$. The absorption in this region can be assigned as CT-type by TD-DFT calculations. Our natural transition orbital (NTO) analysis confirmed that the highest occupied NTO (HONTO) was mainly distributed on A and the lowest unoccupied NTO (LUNTO) on T of TpATtFFO (Figure S1b). The absorption can be attributed to a CT transition through the space between $\mathbf{A}$ and T rather than through the bond. In sharp contrast to the weak absorption, TpAT-tFFO exhibited strong sky-blue emission with a peak maximum wavelength of $485 \mathrm{~nm}$. The PL quantum yield (PLQY or $\Phi_{\mathrm{PL}}$ ) markedly increased from $1.8 \%$ to $84 \%$ after 30 min of Ar bubbling to remove dissolving oxygen $\left(\mathrm{O}_{2}\right)$ 
molecules, which act as a quencher for the triplet excited state of emitters. The excitation wavelength of $365 \mathrm{~nm}$ corresponds to the CT absorption. 98\% of the total PLQY originated from delayed fluorescence, which experiences the process of $\mathrm{S}_{1} \rightarrow \mathrm{T}_{1} \rightarrow \mathrm{S}_{1}$ or cycles of the process. The significantly large jump of the PLQYs indicates that "both the ISC and RISC are rapid" compared with radiative and non-radiative decays. Transient PL decay curves before and after Ar bubbling and the detailed analyses are provided in Figure $3 \mathrm{~b}$ and Table S2. The values of $k_{\mathrm{ISC}}$ and $k_{\mathrm{RISC}}$ were determined to be $5.2 \times 10^{7}$ and $1.2 \times 10^{7} \mathrm{~s}^{-1}$, respectively (Table 1, see Supporting Information for the derivation of the rate constants). The $k_{\mathrm{RISC}}$ value, on the order of $10^{7} \mathrm{~s}^{-1}$, is very large and is the same order of $k_{\mathrm{ISC}}$. To the best of our knowledge, the $k_{\mathrm{RISC}}$ of TpAT-tFFO is the fastest, not only among all TADF systems but also among all organic systems composed only of $\mathrm{H}, \mathrm{C}$ and N. Purely organic materials (materials composed only of nonmetal elements) having $k_{\text {RISC }} \geq 10^{6} \mathrm{~s}^{-1}$ are summarized in Table S3. Using our tFFO strategy, we can expect larger $k_{\mathrm{RISC}}$ values for materials including heavier atoms, such as $\mathrm{P}, \mathrm{S}, \mathrm{Cl}, \mathrm{Br}, \mathrm{I}, \mathrm{Cu}, \mathrm{Pd}, \mathrm{Ag}, \mathrm{Sn}$ and/or $\mathrm{Au}$.

Table 1. Values of rate constants, $k_{\mathrm{r}}^{\mathrm{S}}, k_{\mathrm{nr}}^{\mathrm{S}}, k_{\mathrm{ISC}}$, and $k_{\mathrm{RISC}}$, of TpAT-tFFO (s $\left.{ }^{-1}\right)$. Both the ISC and RISC are rapid compared with radiative and non-radiative decays.

\begin{tabular}{cccc}
\hline$k_{\mathrm{r}}^{\mathrm{S}}$ & $k_{\mathrm{nr}}^{\mathrm{S}}$ & $k_{\mathrm{ISC}}$ & $k_{\mathrm{RISC}}$ \\
\hline $1.1 \times 10^{6}$ & $2.0 \times 10^{5}$ & $5.2 \times 10^{7}$ & $1.2 \times 10^{7}$ \\
\hline
\end{tabular}

In most TADF materials, the lifetime of delayed fluorescence in transient PL experiments is distributed in amorphous films, indicating a distribution of $k_{\mathrm{RISC}}$ values. Some molecules exhibit fast RISC, but some do not. Conversely, the TpAT-tFFO doped film showed a single lifetime in the delayed fluorescence (Figure 3c) as discussed later; all the TpAT-tFFO molecules in the system had very high $k_{\text {RISC }}$ values. These results indicate that effective electron spin inversion occurs in all the TpAT-tFFO 
molecules as expected from the above design concept, although the heavy atom effect cannot be exexpected for molecules composed only of $\mathrm{H}, \mathrm{C}$ and $\mathrm{N}$.

(a)

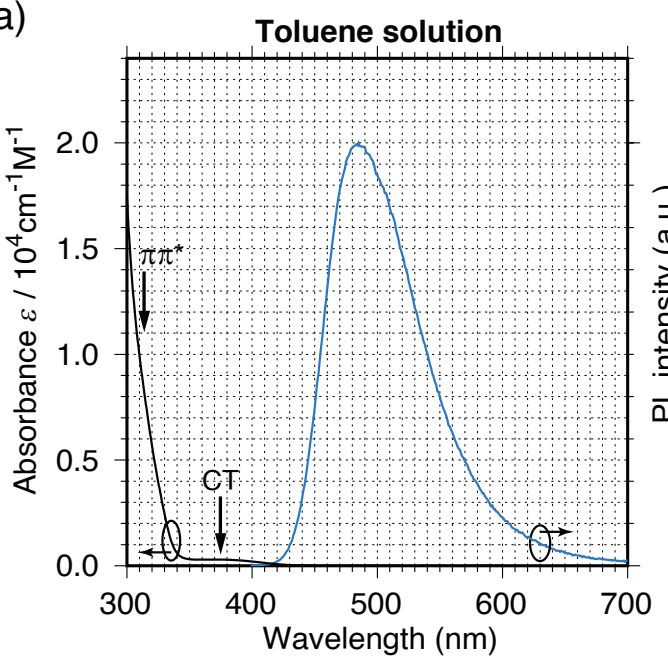

(c)

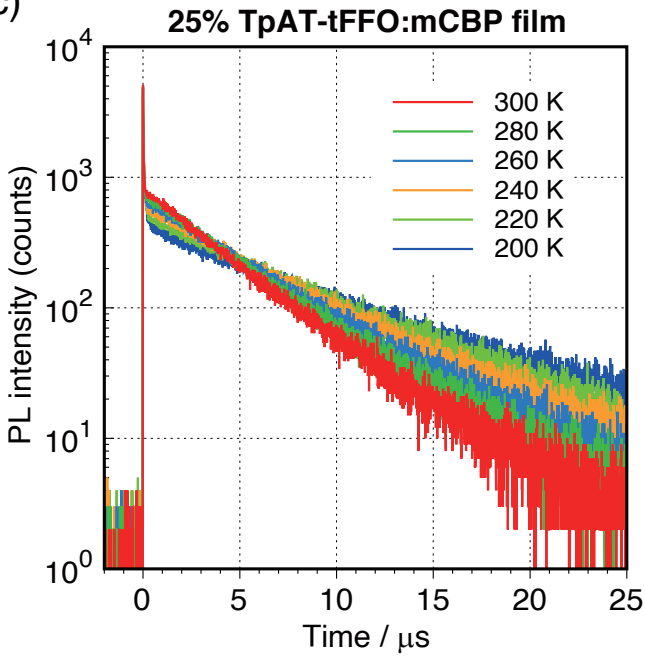

(b)

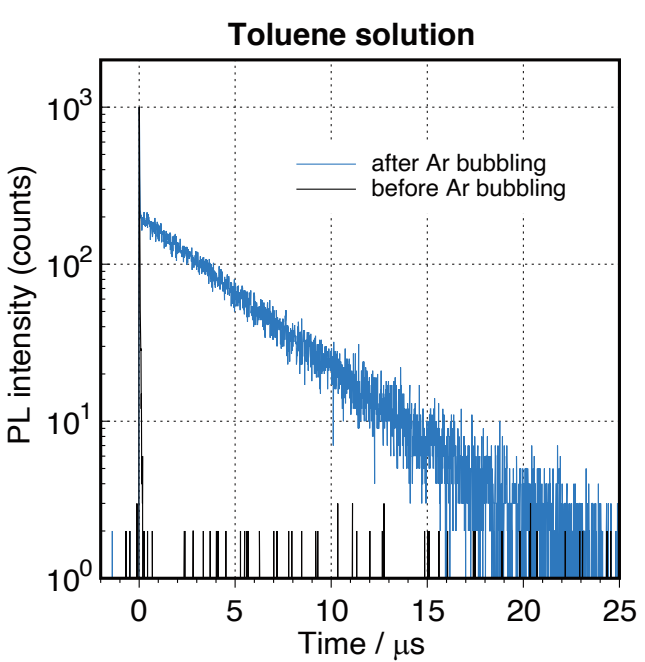

(d)

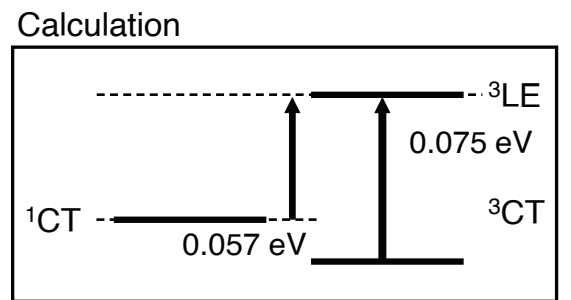

Experiment

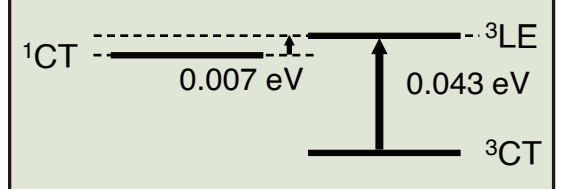

Figure 3. Photoluminescent characteristics. (a) UV-vis absorption and PL spectra of TpAT-tFFO in toluene solution. (b) Transient PL decay curves of TpAT-tFFO in toluene solution before (black) and after (blue) Argon gas bubbling for 30 min. (c) Transient PL decay curves of 25\% TpAT-tFFO:mCBP film from 200 to $300 \mathrm{~K}$. (d) Experimental energy level diagram of TpAT-tFFO in the 25\% TpATtFFO:mCBP film. Corresponding diagram by DFT calculations is also shown. 
We fabricated thin films of TpAT-tFFO both neat and doped into 3,3'-di(9H-carbazol-9-yl)-1,1'biphenyl (mCBP) host and conducted transient PL and PLQY measurements at room temperature $(\sim 300$ K). The PL decay curves of delayed fluorescence in the films were fitted with a single exponential with the lifetime, $\tau_{\mathrm{d}}$, of $3.2 \mu \mathrm{s}$ for the neat film and $4.1 \mu \mathrm{s}$ for the doped film, where the rate-limiting process was radiative decay after RISC. In normal donor-acceptor bonded TADF molecules, the torsion angle, which is flexible in most cases, varies from molecule to molecule in the amorphous aggregates as mentioned in our previous work. ${ }^{15}$ The torsion angle distribution induces a distribution of $\Delta E_{\mathrm{ST}}{ }^{16}$ which results in multi-exponential decay of delayed emission rather than single-exponential. Therefore, TADF performance depends on the molecules having various torsion angles. Our observation of a single exponential decay of the delayed fluorescence for TpAT-tFFO systems indicates a uniform $\Delta E_{\mathrm{ST}}$ even in the amorphous state, which suggests that all emitters exhibit excellent performances when the molecule is appropriately designed. We performed temperature dependent transient PL measurements for a $25 \%$ TpAT-tFFO:mCBP film (Figure 3c). From the Arrhenius analysis, both the ISC and RISC processes were found to have positive activation energies. The activation energies for ISC and RISC, $E_{\mathrm{a}}$ (ISC) and $E_{\mathrm{a}}$ (RISC), were determined to be 0.007 and $0.043 \mathrm{eV}$, respectively. The energy level diagram is shown in Figure $3 \mathrm{~d}$, where the assignments of ${ }^{1} \mathrm{CT},{ }^{3} \mathrm{CT}$ and ${ }^{3} \mathrm{LE}$ were performed based on computational calculations (at the bottom of Figure 3d). A further additional feature of TpAT-tFFO is suppression of concentration quenching: $\Phi_{\mathrm{PL}}$ of $76 \%$ in the $25 \%$ TpAT-tFFO:mCBP film and $\Phi_{\mathrm{PL}}$ of $71 \%$ even in the neat film. Such insensitivity to concentration is beneficial for device optimization, particularly for controlling charge balance in OLEDs. This further suggests great potential of TpAT-tFFO as an excellent emitter for OLEDs. 
(a)

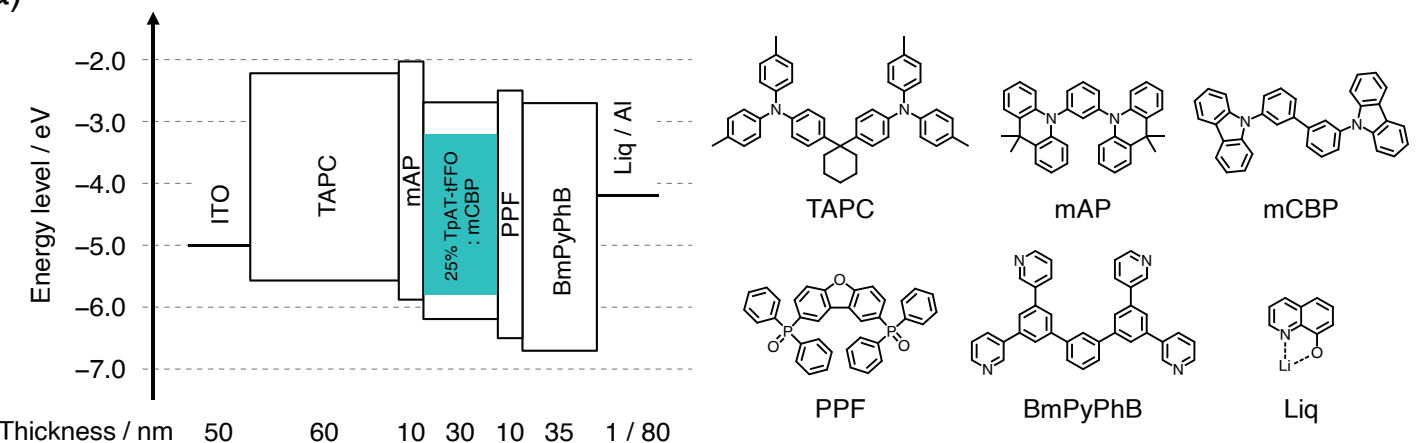

(b)

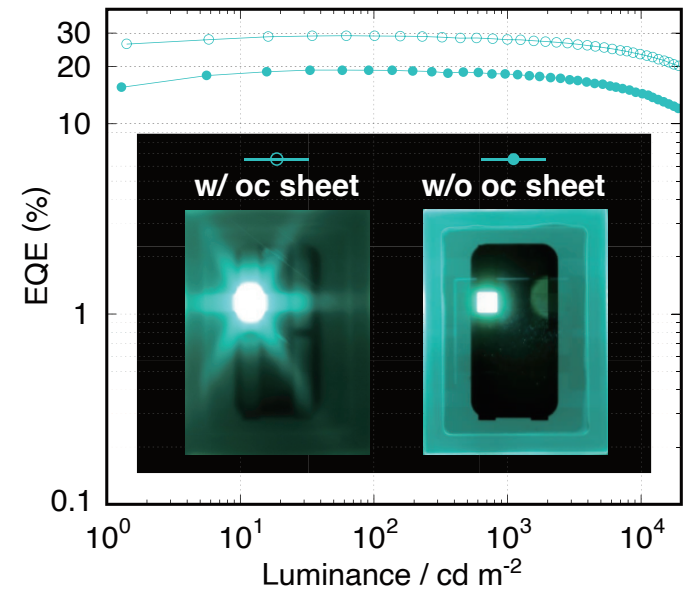

(c)

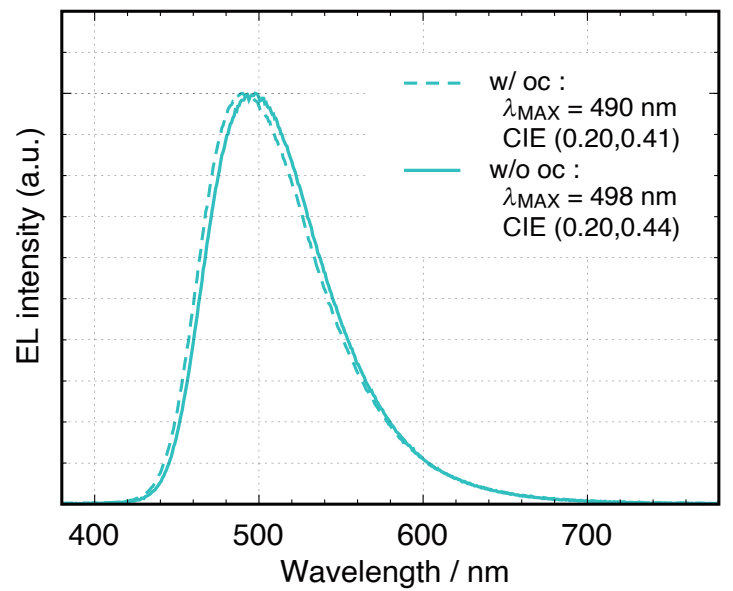

Figure 4. Electroluminescencent device characteristics of TpAT-tFFO-based OLEDs with doping concentration of $25 \% \mathrm{w} /$ and w/o out coupling sheet. (a) Device structure and the chemical structures used for respective layers. (b) EQE-luminance characteristics together with the photographs of the EL emissions. (c) EL spectra at $10 \mathrm{~mA} \mathrm{~cm}^{-2}$. Filled circles in (b) and solid line in (c) indicate results from the device without out-coupling sheet, whereas open circles in (b) and broken line in (c) are results from that with an out-coupling sheet. $\lambda_{\operatorname{MAX}}$ and $\operatorname{CIE}(x, y)$ denote EL peak maximum wavelength and Commission Internationale de l'Eclairage (CIE) coordinates, respectively.

Organic light-emitting diodes. Figure 4 and Table 2 shows the device performances of a TpAT-tFFObased OLED with the device structure, indium-tin-oxide (ITO) $(50 \mathrm{~nm}) / 4,4^{\prime}$-cyclohexylidenebis $[N, N$ bis(4-methylphenyl)benzenamine] (TAPC) (60 nm)/1,3-bis(9,9-dimethylacridin-10(9H)-yl)benzene 
$(\mathrm{mAP})^{17}(10 \mathrm{~nm}) / 25 \%$ TpAT-tFFO:mCBP $(30 \mathrm{~nm}) / 2,8$-bis(diphenylphosphoryl)dibenzo[b,d]furan (PPF) $(10 \mathrm{~nm}) / 1,3$-bis[3,5-di(pyridin-3-yl)phenyl]benzene $(\mathrm{BmPyPhB})(35 \mathrm{~nm}) /$ lithium quinolin-8-olate $(\mathrm{Liq})$ $(1 \mathrm{~nm}) / \mathrm{Al}(80 \mathrm{~nm})$. A device with an optimized doping concentration of $25 \%$ provided a maximum EQE (EQE $E_{\text {MAX }}$ ) of $19.2 \%$ (see Figure S3 and Table S4 for the doping concentration dependence). We obtained EQEs of 19.1 and $18.1 \%$ at 100 and $1,000 \mathrm{~cd} \mathrm{~m}^{-2}$, respectively with sky-blue emission. Moreover, EQEs of 14.4 and $11.6 \%$ were retained even at high luminance of 10,000 and 20,000 $\mathrm{cd} \mathrm{m}^{-2}$, respectively. When an out-coupling sheet was attached to the OLED, EQE $E_{\mathrm{MAX}}$ of $29.0 \%$ and $\mathrm{EQE}$ of $19.7 \%$ at $20,000 \mathrm{~cd} \mathrm{~m}^{-2}$ were realized.

Considering the fast triplet-to-singlet conversion ability of TpAT-tFFO, we further investigated TADF assisted fluorescence (TAF)-OLED ${ }^{18}$ using TpAT-tFFO as the assist dopant. For easy comparison of performances with preceding TAF studies, we used a frequently used conventional blue fluorescent dye, 2,5,8,11-Tetrakis(1,1-dimethylethyl)perylene (TBPe), as the emitter and 9-(4-tertButylphenyl)-3,6-bis(triphenylsilyl)-9H-carbazole (CzSi) as the host (4\%TBPe:26\%TpAT-tFFO:CzSi). From the PL measurement, emission from TBPe was clearly observed in the TpAT-tFFO based TAF system (Figure S4a), indicating Förster resonance energy transfer successfully occurs. It should be noted that the PL (and EL, see below) spectrum of the TAF system is blue-shifted compared with that of the TADF emitter system. The $\Phi_{\mathrm{PL}}$ resulted in $87 \%$. Reflecting the large $k_{\mathrm{RISC}}$ value of TpAT-tFFO, the transient PL experiment provided a very fast lifetime of the delayed component, $\tau_{\mathrm{d}}=0.36 \mu$ s (Figure S4b). Figure 5 and Table 3 show the device performances for the TAF-OLED; ITO (50 nm)/TAPC (60 nm)/mAP (10 nm)/1\%TBPe:24\%TpAT-tFFO:CzSi (20 nm)/PPF (10 nm)/BmPyPhB (35 nm)/Liq (1 $\mathrm{nm}) / \mathrm{Al}(80 \mathrm{~nm})$. The device exhibited blue emission of $\mathrm{CIE}(0.15,0.23)$ with $\mathrm{EQE}_{\mathrm{MAX}}=18.7 \%$. The device reached very high luminance up to $18,000 \mathrm{~cd} \mathrm{~m}^{-2}$ (see also Figure S5) and exhibited arreviated roll-off with EQE of $11.8 \%$ even at high brightness of $10,000 \mathrm{~cd} \mathrm{~m}^{-2}$, which are the best performance 
among blue TAF-OLEDs reported using TBPe as fluorescence dye (Table 3). ${ }^{18-19}$ We believe that the great device performance is attributed to the large $k_{\mathrm{RISC}}$ of TpAT-tFFO. Our tFFO-based TADF materials are found to be also useful for assist dopant of TAF systems, which will realize highly efficient deep-blue OLEDs with narrow EL spactra even at high brightness.

Table 2. Device performances of TpAT-tFFO-based OLEDs with doping concentration of $25 \% \mathrm{w} /$ and w/o out-coupling sheet.

\begin{tabular}{cccccccc}
\hline Emitter & $\mathrm{EQE}_{\mathrm{MAX}}$ & $\mathrm{EQE}_{100}{ }^{a}$ & $\mathrm{EQE}_{1,000}$ & $\mathrm{EQE}_{10,000}$ & $\mathrm{EQE}_{20,000}$ & $L_{\mathrm{MAX}}\left(\mathrm{cd} \mathrm{m}^{-2}\right)$ & $\mathrm{CIE}(x, y)^{c}$ \\
\hline TpAT-tFFO & \multirow{2}{*}{29.0} & 29.0 & 27.6 & 22.8 & 19.7 & 48,930 & $(0.20,0.41)$ \\
(w/ oc sheet) & & $(0.3 \%)^{b}$ & $(4.8 \%)$ & $(21.4 \%)$ & $(32.1 \%)$ & & \\
TpAT-tFFO & \multirow{2}{*}{19.2} & $\begin{array}{c}19.1 \\
(0.4 \%)\end{array}$ & $\begin{array}{c}18.1 \\
(5.4 \%)\end{array}$ & $\begin{array}{c}14.4 \\
(24.7 \%)\end{array}$ & $\begin{array}{c}11.6 \% \\
(38.9 \%)\end{array}$ & 33,870 & $(0.20,0.44)$ \\
(w/o oc sheet) & & $(0.4 \%)$ & & & & \\
\hline
\end{tabular}

${ }^{a} \mathrm{EQE}_{Y}$ denotes EQE value at $Y=\mathrm{cd} \mathrm{m}^{-2} .{ }^{b} \mathrm{EQE}$ roll-off (\%) was shown in parentheses, where EQE rolloff $(\%)=\left(\mathrm{EQE}_{\mathrm{MAX}}-\mathrm{EQE}\right) / \mathrm{EQE}_{\mathrm{MAX}} \times 100 .{ }^{c}$ Color coordinates of Commission Internationale de l'Eclairage (CIE).

Table 3. Device performances of TpAT-tFFO-based TAF OLEDs. Preceding performances of TAFOLEDs are also shown for comparison.

\begin{tabular}{ccccccc}
\hline \multirow{2}{*}{ Reference } & \multirow{2}{*}{ Emitting layer } & \multicolumn{4}{c}{$\mathrm{EQE}(\%)$} & \multirow{2}{*}{$\mathrm{CIE}(x, y)$} \\
\cline { 3 - 6 } & & $\mathrm{EQE}_{\mathrm{MAX}}$ & $\mathrm{EQE}_{1,000}{ }^{a}$ & $\mathrm{EQE}_{5,000}$ & $\mathrm{EQE}_{10,000}$ & \\
\hline This work & $1 \%$ TBPe:24\%TpAT-tFFO:CzSi & 18.7 & 17.1 & 14.4 & 11.8 & $(0.15,0.23)$ \\
Ref.18 & $1 \mathrm{wt} \%$ TBPe:15wt\%ACRSA:DPEPO & 13.4 & 8.7 & N.A. & - & $(0.17,0.30)$ \\
Ref.19a & $0.1 \mathrm{wt} \%$ TBPe:50wt\%CzAcSF:DPEPO & 18.1 & N.A. ${ }^{b}$ & N.A. & - & $(0.15,0.22)$ \\
Ref.19b & TBPe:CzAcSF:DPEPO & 18 & N.A. & N.A. & N.A. & N.A. \\
Ref.19c & TBPe:DMAC-DPS:DPEPO & 18.8 & 13.5 & N.A. & - & $(0.14,0.25)$ \\
Ref.19d & $0.5 \mathrm{wt} \%$ TBPe:5CzCN:DPOBBPE & 19.5 & N.A. & $-{ }^{c}$ & - & $(0.15,0.23)$ \\
\hline
\end{tabular}

${ }^{a} \mathrm{EQE}_{Y}$ denotes EQE value at $Y \mathrm{~cd} \mathrm{~m}^{-2} .{ }^{b} \mathrm{~N}$.A. denotes that data was not assigned. ${ }^{c}-$ denotes that the device do not reach the luminance. 
(a)

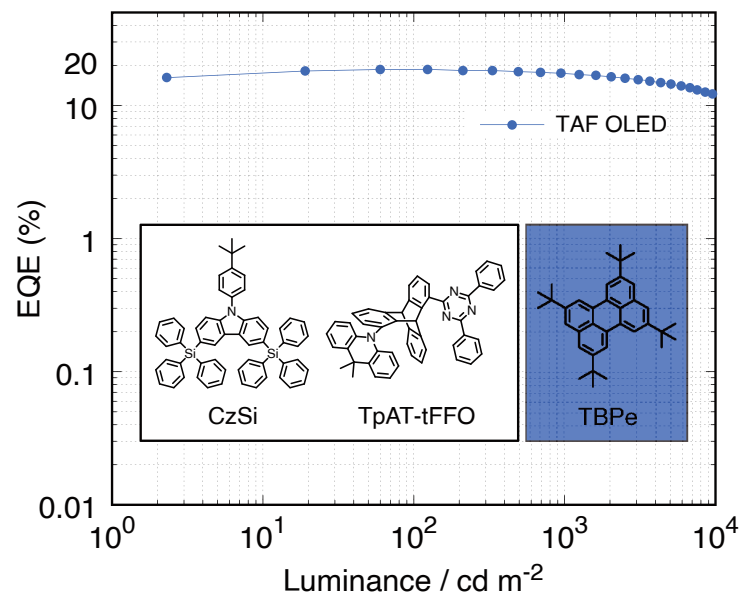

(b)

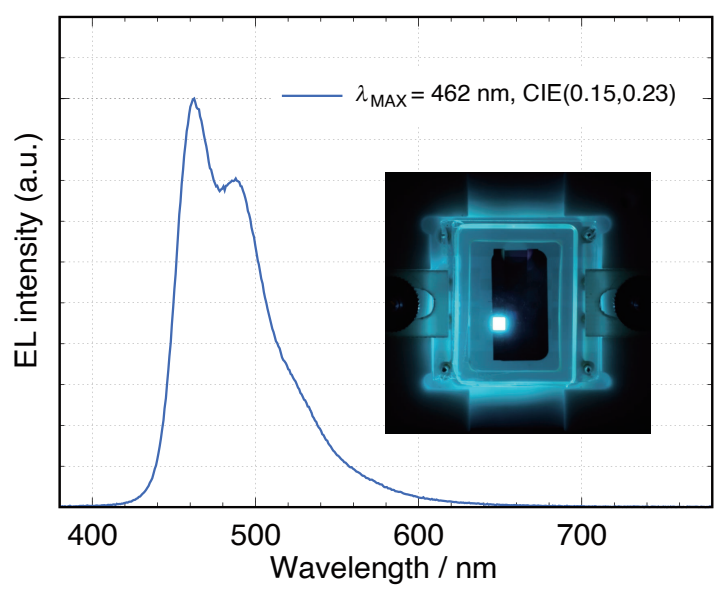

Figure 5. Electroluminescent device characteristics of TpAT-tFFO-based TAF OLED. (a) EQEluminance characteristics the OLED. (b) EL spectra at $10 \mathrm{~mA} \mathrm{~cm}{ }^{-2}$ together with the photograph of the EL emission. 


\section{CONCLUSION}

In this study, we show a novel molecular design concept to achieve very fast RISC in organic molecules. Our molecular design strategy, tFFO, realizes both energy matching of the three states, $E\left({ }^{1} \mathrm{CT}\right) \approx E\left({ }^{3} \mathrm{CT}\right)$ $\approx E\left({ }^{3} \mathrm{LE}\right)$, and significant SOCMEV. This strategy enables and promotes RISC processes even in purely organic molecules. Our example molecule, named TpAT-tFFO, realized a very fast $k_{\text {RISC }}$ exceeding $10^{7}$ $\mathrm{s}^{-1}$, which is the fastest $k_{\mathrm{RISC}}$ reported to date among all organic molecules including TADF ones, and finally achieved great device performance in its application to OLEDs

TpAT-tFFO yields additional features; 1) negligible CT absorption, 2) large $\mathrm{O}_{2}$ sensitivity of PLQY in solution, 3) uniform $\Delta E_{\mathrm{ST}}$ in amorphous films at various temperatures, and 4) negligible concentration quenching. To develop the much sought after deep-blue TADF-based OLEDs, stable host materials with high $\mathrm{T}_{1}$ energies are required; however, the development has been difficult. The use of a neat emitter layer is one way to avoid the host problem. As for emitters, a small Stokes shift is favorable for avoiding red shifting and making the blue emission deeper. However, in that case, exciton self-quenching occurs owing to the inevitable overlap of absorption and emission spectra. The negligible absorption and negligible concentration quenching are considerable advantages for future developments of such deepblue emitters and devices. The transparency in the visible light region is particularly advantageous for multi-color systems where absorption of long wavelength emitters tends to overlap with emission of short wavelength emitters. We also expect that the great $\mathrm{O}_{2}$ sensitivity of TpAT-tFFO in solution will give excellent performance in applications to $\mathrm{O}_{2}$ sensors. The tFFO design can be expanded to various types, various numbers, and various combinations of donors, acceptors and scaffolds. Furthermore, other kinds of functional segments might also be introduced into the scaffolds. Such expansion of tFFO designs will provide novel materials with further improved performances and give insights into fundamental photophysical properties of these materials. 


\section{ASSOCIATED CONTENT}

Supporting Information. This material is available free of charge via the Internet at http://pubs.acs.org.

\section{AUTHOR INFORMATION}

\section{Corresponding Author}

*kaji@scl.kyoto-u.ac.jp

\section{Notes}

The authors declare no competing financial interest.

\section{ACKNOWLEDGMENTS}

This work was supported by JSPS KAKENHI grant nos. 17H01231 and 17J09631. Computation time was provided by the Super Computer System, Institute for Chemical Research, Kyoto University. NMR measurements were supported by the Joint Usage/Research Centre (JURC) at the Institute for Chemical Research, Kyoto University, Japan. We thank Andrew Jackson, PhD, from Edanz Group (www.edanzediting.com/ac) for editing a draft of this manuscript.

\section{- REFERENCES}

(1) Baldo, M. A.; Lamansky, S.; Burrows, P. E.; Thompson, M. E.; Forrest, S. R. Appl. Phys. Lett. $1999,75,4$.

(2) Sasabe, H.; Kido, J. Eur. J. Org. Chem. 2013, 2013, 7653.

(3) Uoyama, H.; Goushi, K.; Shizu, K.; Nomura, H.; Adachi, C. Nature 2012, 492, 234.

(4) Onoue, Y.; Hiraki, K.; Nishikawa, Y. Anal. Sci. 1987, 3, 509. 
(5) (a) Yang, Z.; Mao, Z.; Xie, Z.; Zhang, Y.; Liu, S.; Zhao, J.; Xu, J.; Chi, Z.; Aldred, M. P. Chem. Soc. Rev. 2017, 46, 915. (b) Wong, M. Y.; Zysman-Colman, E. Adv. Mater. 2017, 29, 1605444. (c) Huang, T.; Jiang, W.; Duan, L. J. Mater. Chem. C 2018, 6, 5577.

(6) (a) Endo, A.; Ogasawara, M.; Takahashi, A.; Yokoyama, D.; Kato, Y.; Adachi, C. Adv. Mater. 2009, 21, 4802. (b) Zhu, Z. Q.; Fleetham, T.; Turner, E.; Li, J. Adv. Mater. 2015, 27, 2533. (c) Yersin, H.; Czerwieniec, R.; Shafikov, M. Z.; Suleymanova, A. F. Chemphyschem 2017, 18, 3508. (d) Di, D.; Romanov, A. S.; Yang, L.; Richter, J. M.; Rivett, J. P.; Jones, S.; Thomas, T. H.; Abdi Jalebi, M.; Friend, R. H.; Linnolahti, M.; Bochmann, M.; Credgington, D. Science 2017, 356, 159. (e) To, W. P.; Zhou, D.; Tong, G. S. M.; Cheng, G.; Yang, C.; Che, C. M. Angew. Chem. Int. Ed. 2017, 56, 14036. (f) Hamze, R.; Peltier, J. L.; Sylvinson, D.; Jung, M.; Cardenas, J.; Haiges, R.; Soleilhavoup, M.; Jazzar, R.; Djurovich, P. I.; Bertrand, G.; Thompson, M. E. Science 2019, 363, 601.

(7) (a) Kaji, H.; Suzuki, H.; Fukushima, T.; Shizu, K.; Suzuki, K.; Kubo, S.; Komino, T.; Oiwa, H.; Suzuki, F.; Wakamiya, A.; Murata, Y.; Adachi, C. Nat. Commun. 2015, 6, 8476. (b) Lin, T.-A.; Chatterjee, T.; Tsai, W.-L.; Lee, W.-K.; Wu, M.-J.; Jiao, M.; Pan, K.-C.; Yi, C.-L.; Chung, C.-L.; Wong, K.-T.; Wu, C.-C. Adv. Mater. 2016, 28, 6976.

(8) El-Sayed, M. A. J. Chem. Phys. 1963, 38, 2834.

(9) (a) Marian, C. M. J. Phys. Chem. C 2016, 120, 3715. (b) Dias, F. B.; Santos, J.; Graves, D. R.; Data, P.; Nobuyasu, R. S.; Fox, M. A.; Batsanov, A. S.; Palmeira, T.; Berberan-Santos, M. N.; Bryce, M. R.; Monkman, A. P. Adv. Sci. 2016, 3, 1600080. (c) Gibson, J.; Monkman, A. P.; Penfold, T. J. Chemphyschem 2016, 17, 2956. (d) Etherington, M. K.; Gibson, J.; Higginbotham, H. F.; Penfold, T. J.; Monkman, A. P. Nat. Commun. 2016, 7, 13680. (e) Lyskov, I.; Marian, C. M. J. Phys. Chem. C 2017, 121, 21145. (f) Hosokai, T.; Matsuzaki, H.; Nakanotani, H.; Tokumaru, K.; Tsutsui, T.; Fu- 
rube, A.; Nasu, K.; Nomura, H.; Yahiro, M.; Adachi, C. Sci. Adv. 2017, 3, e1603282. (g) Samanta, P. K.; Kim, D.; Coropceanu, V.; Brédas, J. L. J. Am. Chem. Soc. 2017, 139, 4042. (h) Noda, H.; Nakanotani, H.; Adachi, C. Sci. Adv. 2018, 4, eaao6910.

(10) (a) Kawasumi, K.; Wu, T.; Zhu, T.; Chae, H. S.; Van Voorhis, T.; Baldo, M. A.; Swager, T. M. J. Am. Chem. Soc. 2015, 137, 11908. (b) Shao, S.; Hu, J.; Wang, X.; Wang, L.; Jing, X.; Wang, F. J. Am. Chem. Soc. 2017, 139, 17739. (c) Tsujimoto, H.; Ha, D. G.; Markopoulos, G.; Chae, H. S.; Baldo, M. A.; Swager, T. M. J. Am. Chem. Soc. 2017, 139, 4894.

(11) Frisch, M. J.; Trucks, G. W.; Schlegel, H. B.; Scuseria, G. E.; Robb, M. A.; Cheeseman, J. R.; Scalmani, G.; Barone, V.; Petersson, G. A.; Nakatsuji, H.; Li, X.; Caricato, M.; Marenich, A. V.; Bloino, J.; Janesko, B. G.; Gomperts, R.; Mennucci, B.; Hratchian, H. P.; Ortiz, J. V.; Izmaylov, A. F.; Sonnenberg, J. L.; Williams; Ding, F.; Lipparini, F.; Egidi, F.; Goings, J.; Peng, B.; Petrone, A.; Henderson, T.; Ranasinghe, D.; Zakrzewski, V. G.; Gao, J.; Rega, N.; Zheng, G.; Liang, W.; Hada, M.; Ehara, M.; Toyota, K.; Fukuda, R.; Hasegawa, J.; Ishida, M.; Nakajima, T.; Honda, Y.; Kitao, O.; Nakai, H.; Vreven, T.; Throssell, K.; Montgomery Jr., J. A.; Peralta, J. E.; Ogliaro, F.; Bearpark, M. J.; Heyd, J. J.; Brothers, E. N.; Kudin, K. N.; Staroverov, V. N.; Keith, T. A.; Kobayashi, R.; Normand, J.; Raghavachari, K.; Rendell, A. P.; Burant, J. C.; Iyengar, S. S.; Tomasi, J.; Cossi, M.; Millam, J. M.; Klene, M.; Adamo, C.; Cammi, R.; Ochterski, J. W.; Martin, R. L.; Morokuma, K.; Farkas, O.; Foresman, J. B.; Fox, D. J. Wallingford, CT, 2016.

(12) Sun, H.; Zhong, C.; Brédas, J. L. J. Chem. Theory. Comput. 2015, 11, 3851.

(13) Akinaga, Y.; Ten-no, S. Chem. Phys. Lett. 2008, 462, 348. 
(14) Tsai, W.-L.; Huang, M.-H.; Lee, W.-K.; Hsu, Y.-J.; Pan, K.-C.; Huang, Y.-H.; Ting, H.-C.; Sarma, M.; Ho, Y.-Y.; Hu, H.-C.; Chen, C.-C.; Lee, M.-T.; Wong, K.-T.; Wu, C.-C. Chem. Commun. 2015, $51,13662$.

(15) Wada, Y.; Kubo, S.; Kaji, H. Adv. Mater. 2018, 30, 1705641.

(16) Olivier, Y.; Yurash, B.; Muccioli, L.; D'Avino, G.; Mikhnenko, O.; Sancho-Garcia, J. C.; Adachi, C.; Nguyen, T. Q.; Beljonne, D. Phys. Rev. Mater. 2017, 1, 075602.

(17) Seo, J.-A.; Gong, M. S.; Jeon, S. K.; Lee, J. Y.; Noh, C. H.; Kim, S. H. Dyes and Pigments 2015, $123,254$.

(18) Nakanotani, H.; Higuchi, T.; Furukawa, T.; Masui, K.; Morimoto, K.; Numata, M.; Tanaka, H.; Sagara, Y.; Yasuda, T.; Adachi, C. Nat. Commun. 2014, 5, 4016.

(19) (a) Lee, I. H.; Song, W.; Lee, J. Y.; Hwang, S.-H. J. Mater. Chem. C 2015, 3, 8834. (b) Song, W.; Lee, I.; Lee, J. Y. Adv. Mater. 2015, 27, 4358. (c) Han, S. H.; Lee, J. Y. J. Mater. Chem. C 2018, 6, 1504. (d) Jeon, S. K.; Park, H. J.; Lee, J. Y. ACS Appl. Mater. Interfaces 2018, 10, 5700. 